
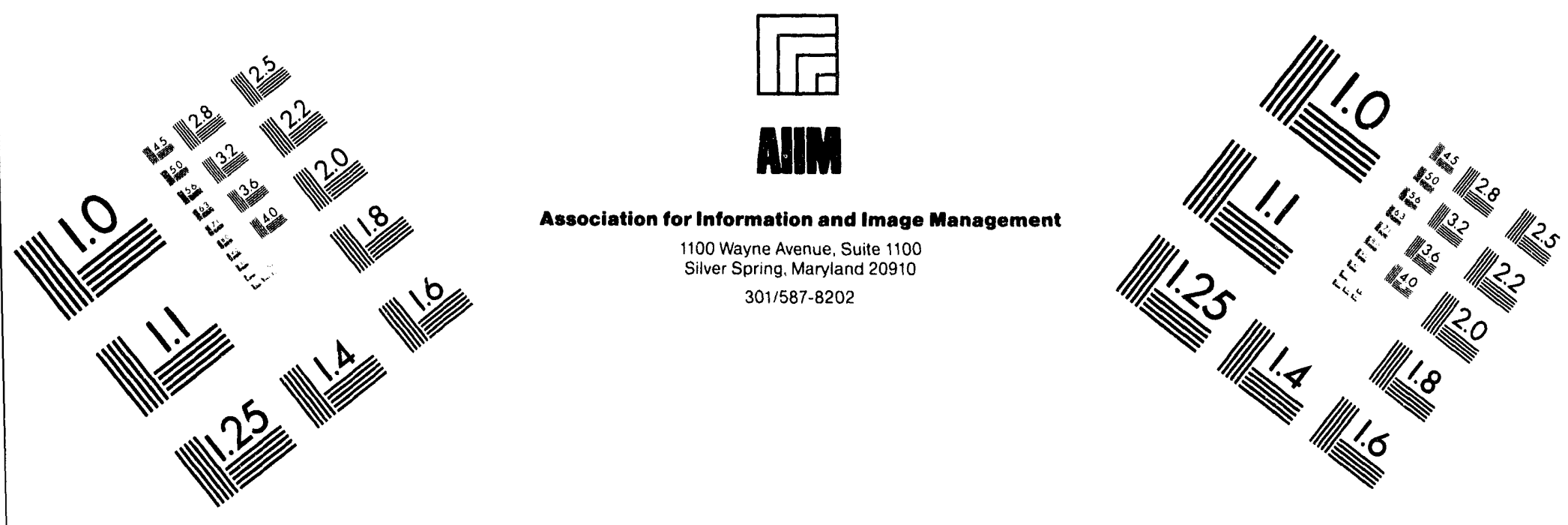

\title{
Centimeter
}

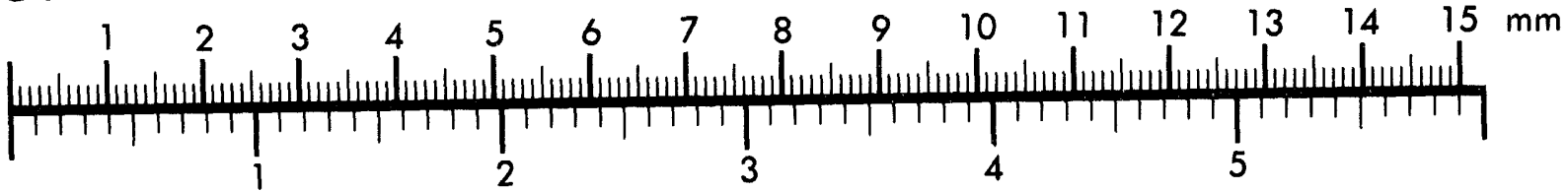
Inches
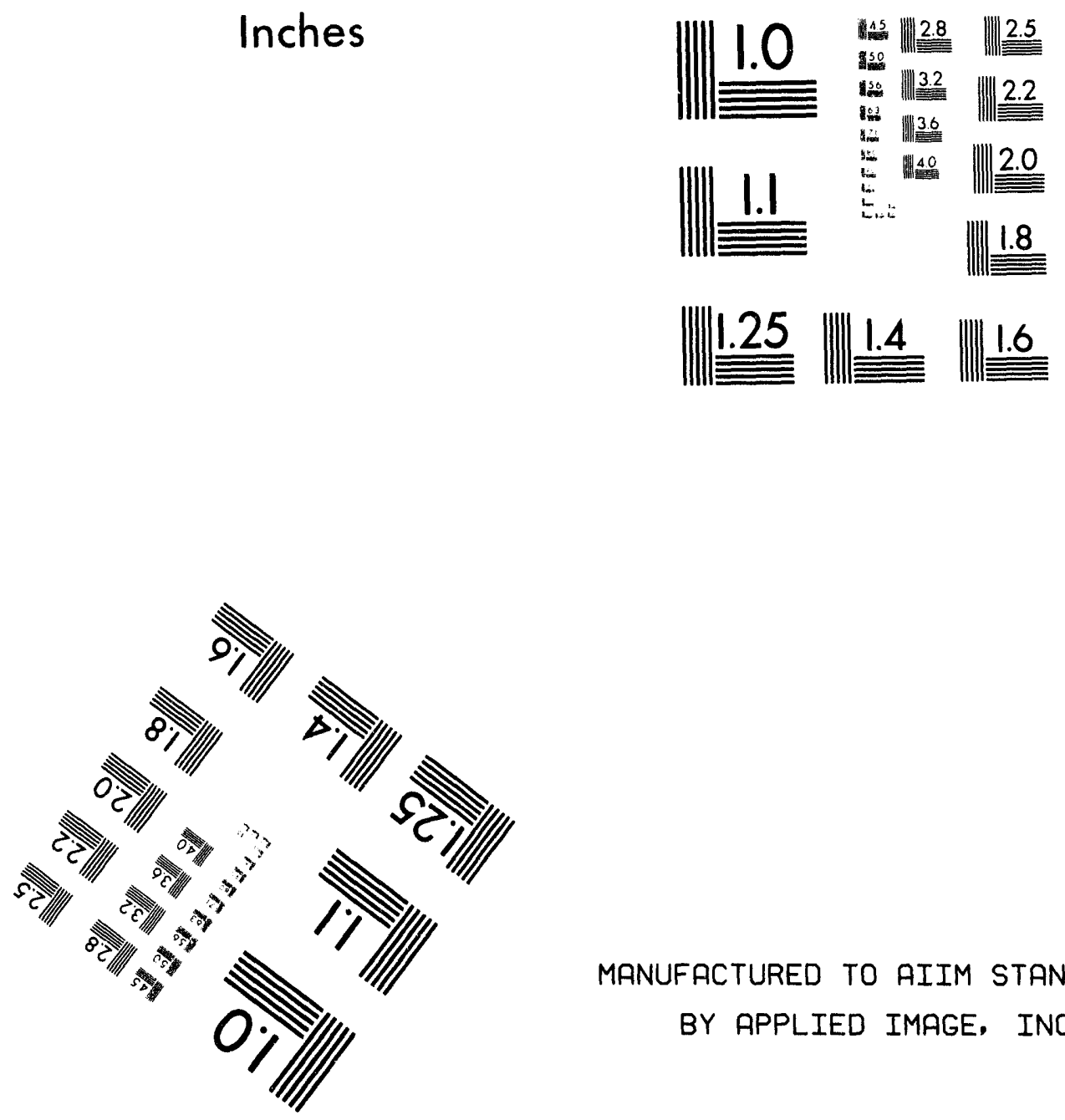

MANUFACTURED TO AIIM STANDARDS BY APPLIED IMAGE, INC.

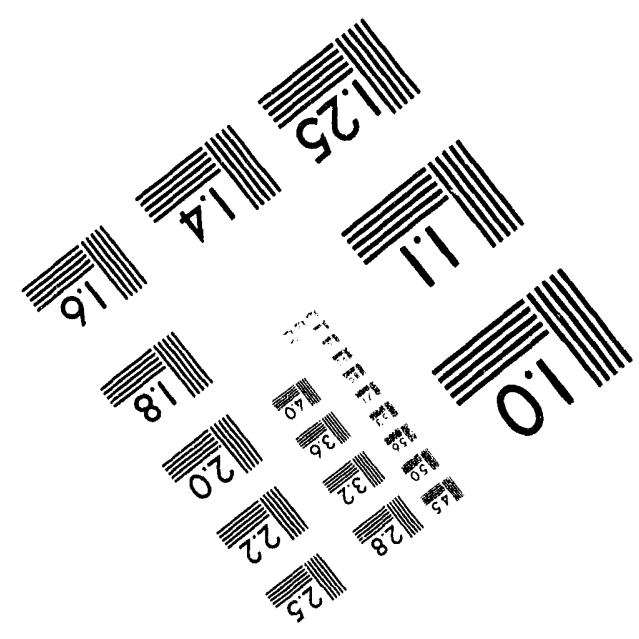



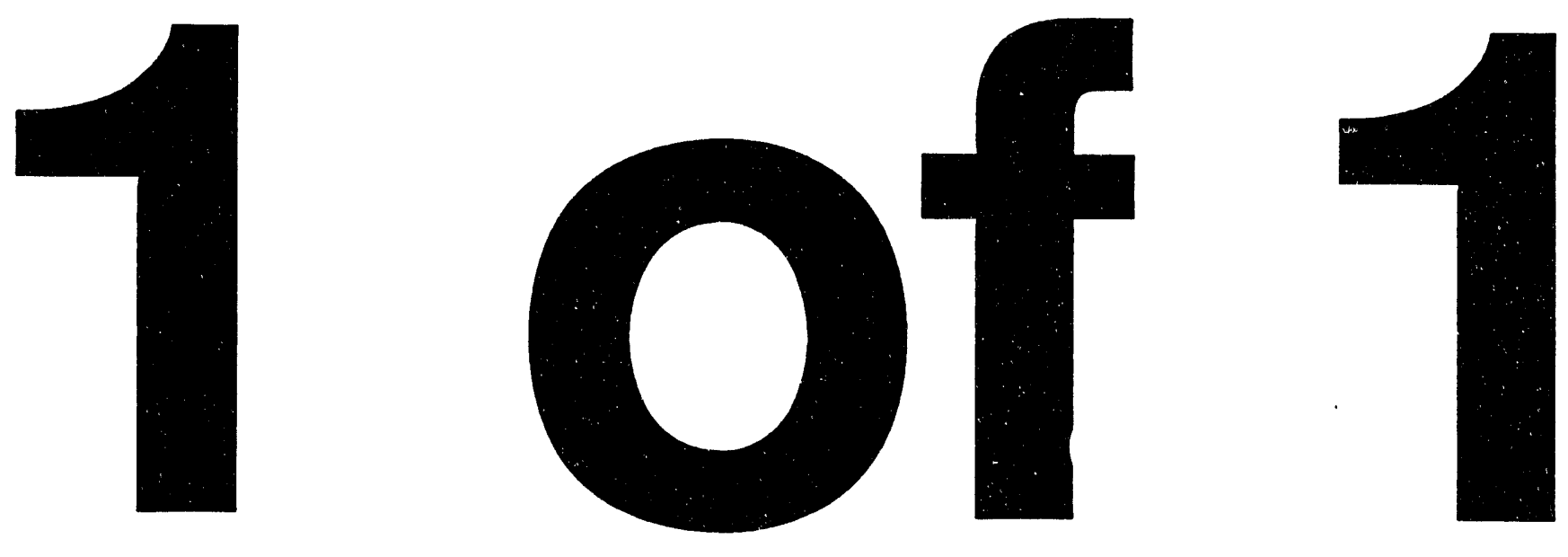


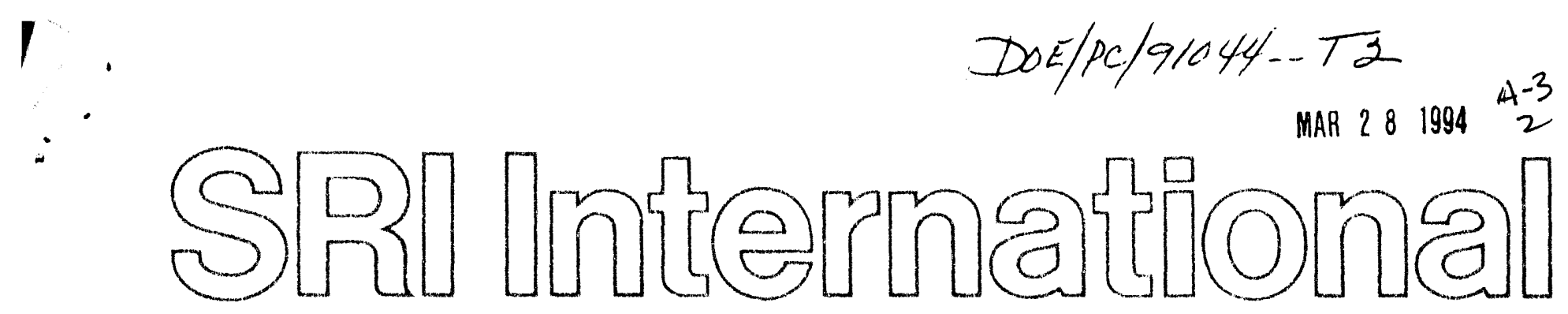

\section{MITIGATING CROSSLINKING REACTIONS THROUGH PRECONVERSION STRATEGIES}

Ripudaman Malhotra, Program Manager Donald F. McMillen, Senior Scientist Molecular Physics Laboratory

SRI Project 2869

MP 94-044

Period Covered: April 1993 to June 1993

Prepared for:

U.S. Department of Energy Pittsburgh Energy Technology Center Acquisition and Assistance Division P.O. Box 10940, M/S 921-118 Pittsburgh, PA 15236-0940

Attn: Michael A. Nowak, Contract Specialist

Contract No. DE-AC22-91PC91044

Approved:

Donald J. Eckstrom, Director Molecular Physics Laboratory

David M. Golden

Vice President

Physical Sciences Division

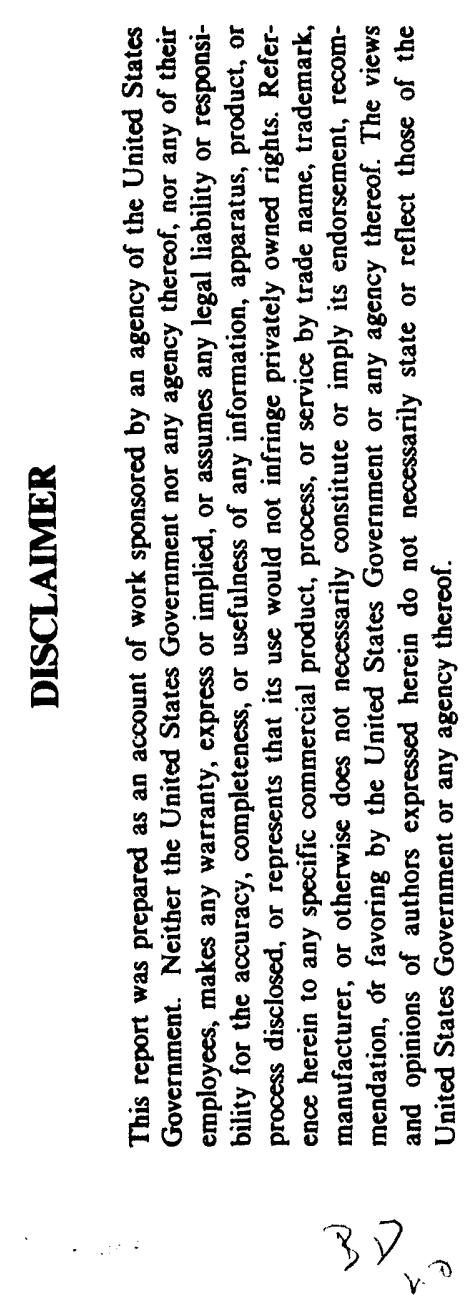




\section{INTRODUCTION}

Liquefaction is generally achieved by heating coals with a donor solvent and, preferably, with a catalyst and hydrogen pressure at temperatures around $425^{\circ} \mathrm{C}$. Attempts to achieve higher conversion by simply using higher temperatures often lead to coking and lower liquid yields. Furthermore, retrograde reactions can lead to crosslink formation (particularly in the case of lowrank coals) even before nominal liquefaction conditions are reached. ${ }^{1}$ Thus, besides the bond cleavage reactions that lead to disintegration of the coal matrix, there are also retrogressive reactions that lead to the formation of new refractory linkages. In many instances, conversion appears to be limited by these retrogressive reactions more than by any inherent lack of reactivity of the coal. ${ }^{2}$

Oxygen functions in general, and specifically carboxylic acids and phenols, have been implicated as important in the retrograde reactions of coals. ${ }^{1-4}$ Furthermore, phenols severely hamper the processability of coals both during liquefaction and during subsequent catalytic upgrading. $5-6$ Thus, substantial benefits could be realized if coals were even partially deoxygenated before liquefaction. Ideally, this deoxygenation would be achieved in a preconversion step, before widespread retrogression occurs.

Deoxygenation of phenols is chemically the most difficult heteroatom removal to achieve, 7 particularly for heterogeneous systems, where access of a solid catalyst (even if very finely divided) to the depth of an organic matrix is quite limited. Furthermore, some phenolic structures that deoxygenate readily also couple very readily during heatup, often before temperatures at which coals become fluid (and easily contactable by heterogeneous catalysts) and before temperature at which thermal hydrogen-transfer reactions lead to bond cleavage. 3,8 Carboxyl groups have also been associated with crosslinking. Solomon and coworkers have shown that decarboxylation, particularly in the low temperature regime of $200^{\circ}$ to $250^{\circ} \mathrm{C}$, correlates with crosslinking. ${ }^{4}$ Thus, pretreatments that can effectively deoxygenate phenols or decarboxylate without the attendant crosslinking constitute a technical challenge whose resolution would greatly facilitate utilization of coal through direct liquefaction.

The combination of $\mathrm{CO}$ and water is well recognized as a thermodynamically powerful but kinetically limited reducing system. It has been extensively explored as a liquefaction system for low-rank coals by Appell ${ }^{9}$ and by researchers in North Dakota, ${ }^{10}$ following on much earlier work ${ }^{11}$ in Germany. Since the utility of the system has been severely hampered by the requirement for high partial pressures of water, effective promoters must be found if it is to be effective under pretreatment conditions for removal of phenolic $\mathrm{OH}$ and for crosslink cleavage in low-rank coals. Since $\mathrm{CO} /$ water easily deoxygenates polycyclic phenols such as anthrone, and since the overall thermodynamic driving force for deoxygenation of monocyclic phenols is essentially identical to that for polycyclic phenols, the potential exists for greatly accelerating the reaction with promoters. 


\section{OBJECTIVES}

The ultimate goal of this research is to help develop preconversion techniques that will mitigate crosslinking reactions and thereby substantially increase liquid yields during subsequent liquefaction. The immediate objective is to determine the potential for augmenting pretreatment of low-rank coals through the use of electron-transfer agents. This potential will be explored in laboratory studies through determination of the impact on the evolution of oxygen functions, crosslinking, and conversion. The pretreatments explored include several that hold promise for effecting deoxygenation (or other reduction), for example, treatment with $\mathrm{CO} / \mathrm{water} / \mathrm{base}$ and hydroquinones or other electron-transfer agents in various combinations. The effects of these pretreatments on functional group distribution, macromolecular structure, and liquefaction are to be compared with those that have shown promise in the past for improved conversions, such as simple hydrothermal pretreatment, mild hydrogenation with dispersed catalysts, and demineralization.

Additional objectives are to improve test procedures for assessing the effect of the pretreatment on subsequent liquefaction and achieve also some understanding of the chemical origins of the effects observed. These tests are: (1) proton magnetic resonance thermal analysis 12,13 (PMRTA) for determining the effect of pretreatment on fluidity as liquefaction conditions (temperature, pressure) are approached; and (2) a TGA-based simulated distillation for convenient measurement of product volatility following small scale batch liquefaction. The purpose of the PMRTA test is to gain additional insight into whether beneficial pretreatments primarily affect pre-existing crosslinks in the coals or whether they primarily limit additional crosslinking during liquefaction. The TGA-based simulated distillation test is being developed so that we can obtain conversion data and also assess the nature of the product (distillation profile) instead of only a single point measure of conversion such as wt \% conversion to THF-solubles or the yield of $975^{\circ} \mathrm{F}$ - distillates. 


\section{WORK PERFORMED}

\section{EXPERIMENTAL PROCEDURES}

Pretreatment. The pretreatment experiments were performed in an unstirred, 90-ml 304 stainless steel reactor fitted with a quartz insert and heated in a fluidized sand bath. The basic pretreatment condition involved heating in liquid water at $350^{\circ} \mathrm{C}$ for 30 minutes, under a $\mathrm{CO}$ partial pressure of 500 psi (cold). Each pretreatment test used 10 grams (2 ampoules) of -100 mesh Argonne Premium Coal Sample Bank Wyodak or Zap Lignite, to which $15 \mathrm{~mL}$ of a 2 vol \% solution of methanol (to facilitate wetting of coal) in deionized, de-oxygenated water. The reactor heatup time was $\sim 20$ minutes, and the total reaction time was 50 minutes. After cooling in a cold sand bath, the excess water was removed with three stages of centrifuging and pipetting off the supernatant liquid. One third of the wet coal was stored under argon in a freezer for future analysis, and the remainder was subjected to liquefaction on the same day that the pretreatment was run.

Liquefaction. The liquefaction tests of the pretreated coals were run in $40-\mathrm{mL}$ horizontally held, vertically shaken (ca. $500 \mathrm{cps}, 5 / 8$-in stroke) 316 stainless steel microautoclaves. The liquefaction tests were all run on about 6 grams of coal (as received basis) at $430^{\circ} \mathrm{C}$ for 50 minutes in tetralin (solvent:coal 2:1, on an as-received basis), under 1000 psi (cold) hydrogen. After cooling in sand- and dry-ice baths, the contents of the reactor were transferred to a beaker with $200 \mathrm{ml}$ hexane, sonicated for 10 minutes, and filtered through a $0.45 \mu \mathrm{m}$ PTFE membrane filter. The filter residue was dried at $76^{\circ} \mathrm{C}$ overnight in a vacuum oven at $\sim 0.2$ torr. The weight of the dried residue was determined and used to calculate the wt \% conversion to hexane-soluble material.

We have relied on the residue-based conversion to hexane solubles as a rough measure (albeit generally an overestimate) of conversion to distillate material. The baseline pretreatment and liquefaction conditions seem to be appropriate for this conversion criterion: pretreatment in water at $350^{\circ} \mathrm{C}$ for 30 minutes, followed by liquefaction in tetralin at $420^{\circ} \mathrm{C}$ for one hour yields about $40 \%$ conversion (maf) to hexane solubles. We judged that this was a high enough conversion to secondary liquefaction products to have some relevance to high-severity two-stage liquefaction, but low enough to leave latitude for observing the benefits of improved pretreatment on the initial coal conversion reactions.

\section{RESULTS AND DISCUSSION}

\section{Pretreatment and Liquefaction of Wyodak and Zap Lignite Coals}

In the last quarterly report, we presented the results of liquefaction of Wyodak subbituminous coal and Zap lignite following various pretreatments designed to effect 
deoxygenation and minimize crosslinking. Based upon recent studies at SRI and other laboratories, we used hydrothermal pretreatment under $\mathrm{CO}$ pressure at $350^{\circ} \mathrm{C}$ as a baseline for both Wyodak and Zap coals. These conditions provide modest improvement in subsequent liquefaction or coprocessing experiments. We compared the liquefaction yields obtained from baselinepretreated coals with those obtained when base, electron-transfer agent, carbon disulfide, and ferrous sulfate are added to the pretreatment in various combinations. These results are summarized in Tables 1 and 2 for Wyodak and Zap coals, respectively (repeated from previous quarterly report to facilitate discussion). As described under Experimental Procedures, the conversion diagnostic was the wt\% (daf) of hexane-insoluble obtained after the pretreatment and subsequent liquefaction.

The results in Table 1 reflect a precision of 2-3wt\% hexane insolubles and a maximum total improvement of about $5 \mathrm{wt} \%$ daf in hexane-insolubles for pretreatment agents, beyond the benefit provided by $350^{\circ} \mathrm{C}$ hydrothermal pretreatment. There appears to be little if any benefit provided by hydroquinone, once a very low level of base and/or $\mathrm{CS}_{2}$ are present. The greatest limit to precision appears to be the steep dependence of conversion on temperature. In fact later experiments show that the high yield (low $\mathrm{HI}$ ) observed in Run JC-14 ( $\left.\mathrm{Na}_{2} \mathrm{CO}_{3} / \mathrm{HQ}\right)$ is primarily due to the higher temperature, rather than to the combination of promoters and the 48-h "hold" time that the pretreated coal experienced in this run before the liquefaction test could be performed. Although the temperature of the fluidized sand bath is controlled to within $\pm 2^{\circ} \mathrm{C}$, the rate of reactor heat-up is dependent on the degree of fluidization and the location of the reactor in the sand bed. Notwithstanding these fluctuations in net reaction severity, the results in Table 1 give little indication that hydroquinone provides any added benefit over base and/or $\mathrm{CS}_{2}$ under the pretreatment conditions employed here.

Carbon disulfide was tested (as a source of $\mathrm{H}_{2} \mathrm{~S}$ ) as one of the promoters because these low-rank coals, being low in sulfur, are known to benefit, sometimes very substantially, 14 from addition of $\mathrm{CS}_{2}$ or other sources of sulfur. We did not wish any benefits observed for hydroquinones or other added electron transfer agents to be misleadingly high because of the low sulfur content of these coals.

The results obtained for the Zap coal, shown in Table 2, indicate the following:

1) The addition of $0.1 \mathrm{wt} \% \mathrm{Na}_{2} \mathrm{CO}_{3}$ (on the added water) yields a small ( 2 wt\%) improvement in the amount of hexane insolubles.

2) By itself, the addition of $6.3 \mathrm{wt} \% \mathrm{CS}_{2}$ (on the raw coal) does not lead to any improvement in the hexane insolubles.

3) The addition of $2.5 \mathrm{wt} \% \mathrm{CS}_{2}$ (on the raw coal) together with base leads to a substantial $(\sim 9 \mathrm{wt} \%)$ improvement in the hexane insolubles. 
Table 1

EFFECT OF PRETREATMENT ON CONVERSION OF WYODAK COAL

IN THERMAL BATCH LIQUEFACTION

\begin{tabular}{|c|c|c|c|c|c|c|}
\hline \multirow[b]{3}{*}{ Expt No. } & \multicolumn{4}{|c|}{ Pretreatment ${ }^{a}$} & \multirow[b]{3}{*}{$\begin{array}{l}\text { Liquefaction } \\
\text { Temp. }\left({ }^{\circ} \mathrm{C}\right)^{b} \\
\end{array}$} & \multirow[b]{3}{*}{$\begin{array}{c}\text { Hexane } \\
\text { Insolublesc } \\
\end{array}$} \\
\hline & \multicolumn{3}{|c|}{ Additives ${ }^{d}$} & \multirow{2}{*}{$\begin{array}{c}\text { Gas } \\
\begin{array}{c}500 \mathrm{psi} \\
\text { (cold) }\end{array} \\
\end{array}$} & & \\
\hline & $\begin{array}{l}0.1 w t \% \\
\mathrm{Na}_{2} \mathrm{CO}_{3}{ }^{d} \\
\end{array}$ & $\begin{array}{c}5 w t \% \\
p-H Q^{e, f}\end{array}$ & $\begin{array}{l}2.5 w t \% \\
\mathrm{CS}_{2}{ }^{\theta, g} \\
\end{array}$ & & & \\
\hline JC2 & & & & Ar & 420 & 55.0 \\
\hline $\mathrm{JC} 2 \mathrm{~A}$ & & & & $\mathrm{Ar}$ & 430 & 50.2 \\
\hline $\mathrm{JC} 3$ & & & & co & 430 & 52.5 \\
\hline $\mathrm{JC}_{12}$ & & $x$ & & $\mathrm{CO}$ & 430 & 53.8 \\
\hline $\mathrm{JC}_{14}$ & $x$ & $x$ & & $\mathrm{CO}$ & $440^{h}$ & 41.3 \\
\hline JC14B & $x$ & $x$ & & $\mathrm{CO}$ & 430 & 48.0 \\
\hline $\mathrm{JC} 14 \mathrm{C}$ & $x$ & $x$ & & $\mathrm{CO}$ & 430 & 47.8 \\
\hline$J C 14 D$ & $x$ & $x$ & & co & $430^{h}$ & 49.9 \\
\hline$J_{C} 16$ & $x$ & $x$ & $x$ & co & 430 & 49.9 \\
\hline $\mathrm{JC}_{17}$ & & & $x$ & CO & 430 & 44.8 \\
\hline $\mathrm{JC} 18$ & $x$ & $x$ & $x$ & co & 430 & 50.5 \\
\hline
\end{tabular}

a. $10.0 \mathrm{~g} \mathrm{coal} ; 15 \mathrm{ml} \mathrm{H} \mathrm{H}_{2} \mathrm{O}$, mixed but unstirred; $53 \mathrm{~min}$ at $350^{\circ} \mathrm{C}$.

b. $1 \mathrm{hr}$; $1000 \mathrm{psi} \mathrm{H}_{2}$ (cold)

c. Defined as \%daf coal that was insoluble in $200 \mathrm{ml}$ hexane.

d. As wt\% of the added $\mathrm{H}_{2} \mathrm{O}$.

e. As wt\% of raw coal.

f. $\mathrm{p}-\mathrm{HQ}=\mathrm{p}$-hydroquinone

g. Calculated to produce $\mathrm{H}_{2} \mathrm{~S}$ at $13 \%$ the level of $\mathrm{H}_{2}$ pressure.

h. Pretreated coal allowed to sit for $48 \mathrm{hrs}$ (at room temperature, under $\mathrm{CO}$ pressure) after $350^{\circ} \mathrm{C}$ pretreatment. 
Table 2

EFFECT OF PRETREATMENT ON CONVERSION OF ZAP LIGNITE IN THERMAL BATCH LIQUEFACTION

\begin{tabular}{|c|c|c|c|c|c|c|c|c|}
\hline & \multicolumn{6}{|c|}{ Pretreatment a } & \multirow[b]{3}{*}{$\begin{array}{l}\text { Liquefaction } \\
\text { Temp. }\left({ }^{\circ} \mathrm{C}\right)^{\mathrm{b}}\end{array}$} & \multirow[b]{3}{*}{$\begin{array}{l}\% \text { Hexane } \\
\text { Insolubles } \mathrm{c}\end{array}$} \\
\hline & \multicolumn{5}{|c|}{ Additives (wt\%) } & \multirow{2}{*}{ 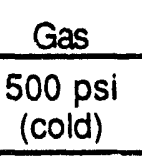 } & & \\
\hline Exp. & $\mathrm{Na}_{2} \mathrm{CO}_{3} \mathrm{~d}$ & $\mathrm{p}-\mathrm{HQ}^{\mathrm{e}, f}$ & $\mathrm{CS}_{2}{ }^{\mathrm{\theta}}$ & $\mathrm{FeSO}_{4} \mathrm{~g}$ & TAME ${ }^{\theta, h}$ & & & \\
\hline JC18A & & & & & & CO & 430 & 53.4 \\
\hline $\mathrm{JC}_{19}$ & 0.1 & 5 & & & & CO & $\approx 410^{i}$ & 59.1 \\
\hline $\mathrm{JC}_{2} \mathrm{O}$ & 0.1 & & & & & co & 430 & 51.5 \\
\hline $\mathrm{JC} 22$ & 0.1 & 5 & & & & Co & 430 & 51.5 \\
\hline $\mathrm{JC} 28$ & 0.1 & 5 & & & & CO & 430 & 51.1 \\
\hline $\mathrm{JC24}$ & 0.1 & 5 & $2.5^{j}$ & & & $\mathrm{CO}$ & 430 & 44.5 \\
\hline JC26 & 0.1 & 5 & $2.5^{j}$ & & & $\mathrm{CO}$ & 430 & 45.1 \\
\hline $\mathrm{JC25}$ & 0.1 & & $2.5^{j}$ & & & $\mathrm{CO}$ & 430 & 47.5 \\
\hline $\mathrm{JC27}$ & 0.1 & & $2.5^{j}$ & & & co & $430^{k}$ & 44.8 \\
\hline $\mathrm{JC34}$ & 0.1 & & $2.5^{i}$ & & & CO & 430 & 44.3 \\
\hline JC30 & 0.1 & & & & 4.8 & co & 430 & 49.7 \\
\hline JC29 & & & 6.3 & $2.5^{1}$ & & co & 430 & 43.6 \\
\hline JC32 & & & 6.3 & $2.5^{\prime}$ & & co & 430 & 45.2 \\
\hline JC33 & $m$ & & 6.3 & $2.5^{1}$ & & CO & 430 & 44,2 \\
\hline JC31 & & & 6.3 & & & $\mathrm{CO}$ & 430 & 53.8 \\
\hline
\end{tabular}

a. $\quad 10.0 \mathrm{~g} \mathrm{coal;} 15 \mathrm{ml} \mathrm{H} \mathrm{O}_{2}$, mixed but unstirred; $53 \mathrm{~min}$ at $350^{\circ} \mathrm{C}$.

b. Unless noted, reaction times are $1 \mathrm{hr}$ under $1000 \mathrm{psi} \mathrm{H}_{2}$ (cold)

c. Defined as the percent of the organic portion of the coal that was insoluble in $200 \mathrm{ml}$ hexane.

d. As $w$ t\% of the added $\mathrm{H}_{2} \mathrm{O}$.

e. As wt\% of raw coal.

f. $\quad \mathrm{p}-\mathrm{HQ}=\mathrm{p}$-hydroquinone

g. As $\mathrm{FeSO}_{4} \cdot 7 \mathrm{H}_{2} \mathrm{O}$; weight percentages are on raw coal and refer to the nominal amount of unhydrated material.

h. TAME = tetrakis (dimethylamino) ethylene

i. Fluidized sand bath temperature set at $430^{\circ} \mathrm{C}$, but temperature did not recover after insertion of reactor, apparently due to excessive air flow through bath.

j. Calculated to produce $\mathrm{H}_{2} \mathrm{~S}$ at $\approx 13 \%$ the level of $\mathrm{H}_{2}$ ostensibly available from the water gas shift reaction.

k. Fluidized sand bath temperature set at $430^{\circ} \mathrm{C}$, but temperature dropped to $381^{\circ} \mathrm{C}$ and recovered to $400^{\circ} \mathrm{C}$ only after $15 \mathrm{~min}$. Total reaction time $75 \mathrm{~min}$.

I. Washed with several aliquots of $\mathrm{H}_{2} \mathrm{O}$ after pretreatment; calculated to remove $>99 \%$ of material freely soluble in pretreatment water. Initial ratio $\mathrm{CS}_{2} / \mathrm{FeSO}_{4}(\mathrm{~mol} / \mathrm{mol})=5$.

m. Final $\mathrm{H}_{2} \mathrm{O}$ wash after pretreatment (note I) contained $0.1 \mathrm{wt} \% \mathrm{Na}_{2} \mathrm{CO}_{3}$. 
4) The addition of $2.5 \mathrm{wt} \% \mathrm{p}$-hydroquinone ( $\mathrm{p}-\mathrm{HQ}$, on the raw coal) to a 99999 pretreatment system containing either base alone or a base/CS 2 mixture does not lead to improvement in the hexane insolubles when compared to the same system without added $\mathrm{p}-\mathrm{HQ}$.

5) The addition of a mixture of $4.8 \mathrm{wt} \%$ TAME (on the raw coal) and $0.1 \mathrm{wt} \%$ base leads to a small $(1.5 \mathrm{wt} \%)$ improvement in the hexane insolubles when compared to the base-only case. TAME is thus slightly more effective than p$\mathrm{HQ}$, but stili less effective than the base/CS 2 mixture.

6) The addition of $2.5 \mathrm{wt} \% \mathrm{FeSO}_{4}$ together with $6.3 \mathrm{wt} \% \mathrm{CS}_{2}$ yields a substantial $(\sim 9 \mathrm{wt} \%)$ improvement in the hexane insolubles.

7) If the above $\mathrm{FeSO}_{4} / \mathrm{CS}_{2}$ system is washed with base prior to the liquefaction (after the pretreatment), there is no further improvement (or degradation) in the amount of hexane insolubles when compared with the unwashed system.

As detailed above, the two most promising systems involve pretreatment with a mixture of either base/CS 2 or $\mathrm{FeSO}_{4} / \mathrm{CS}_{2}$. Both of these treatments yield an improvement of about $9 \mathrm{wt} \%$ in the amount of hexane insolubles. In part, these results are at least qualitatively expected. The addition of iron and sulfur compounds, particularly to low rank coals poor in these two elements, is well known to be beneficial.

The electron transfer agents p-HQ and TAME (tetrakisdimethylaminoethylene) did not yield the same degree of improvement as $\mathrm{FeSO}_{4}$ or $\mathrm{CS}_{2}$. HQ addition did not help at all when either base or base/CS 2 were already present. TAME was somewhat more effective, but did not help as much as the already-known-to-be-useful additives $\mathrm{CS}_{2}$ and $\mathrm{FeSO}_{4}$. Thus, these electron transfer agents do not appear to offer great promise, at least as pretreatment agents. We are somewhat surprised to see essentially no additional benefit from hydroquinone, given that it and related hydroquinones have been shown ${ }^{15}$ to be of significant benefit under liquefaction conditions, and that hydroquinone derivatives are used, in their oxidized forms, as hydrogen-transfer agents in synthetic procedures to promote low-temperature de-hydrogenation. Two possible reasons for the obscrved lack of benefit are (1) the added hydroquinone was largely removed when the excess water was removed after the pretreatment step, and was therefore not present during liquefaction, where it is known to be beneficial, and/or (2) the low-rank coals are themselves already indigenous sources of catechol and other hydroquinone species.

The removal of hydroquinone after the pretreatment step was intentional, since the purpose was to explore the benefits of these promoters under pretreatment conditions. But in fact, the removal of excess water after pretreatment could also remove some of the indigenous hydroquinones which are generated from the coal at about $300^{\circ} \mathrm{C}$, and could thereby actually be detrimental to the subsequent liquefaction. In contrast with the probable removal of much of the added and indigenously generated hydroquinones, the added $\mathrm{FeSO}_{4}$ and/or added $\mathrm{CS}_{2}$, by virtue of conversion to iron sulfide, will be at least partially retained when the excess pretreatment water is removed. Therefore these latter additives may be positively impacting the liquefaction, having been favorably activated during the pretreatment. 
Evolution of Oxygen Functional Groups. Although the deoxygenation of singlering phenols under mild liquefaction conditions in general, or under $\mathrm{CO} /$ water conditions in particular, is not facile, it is thermodynamically just as favorable as the kinetically facile deoxygenation of polycyclic phenols. There was good reason to hope that the right combination of electron-transfer agents would substantially promote it. The monocyclic phenols have a more endothermic first step (reduction of keto-form) and a much more exothermic second step (water elimination) so as to have a net deoxygenation thermochemistry that is essentially identical to that for the easily reduced polycylic pheriols. Successful promotion requires the chemical potential of the reducing system be increased in order to accomplish the first step. This may require not only a catalyst, but also an effective reservoir of reducing agent to keep the chemical potential high even after some reduction has taken place. However, direct oxygen analysis (as well as oxygen by difference) of pretreated coals shows that all of the pretreatments tested here, including baseline conditions, reduce the O-content of Zap lignite from $20 \mathrm{wt} \%$ to about $15.5 \mathrm{wt} \%$ and for the Wyodak coal from $18 \mathrm{wt} \%$ to about $14 \mathrm{wt} \%$. Similarly, very little difference with respect to hydrogen content was observed between the different pretreatments. ${ }^{* *}$ It is interesting that the pretreatment conditions employed did not accomplish the additional deoxygenation that was desired, but nevertheless did result in modest improvements in liquefaction yields.

The modest $\mathrm{CO}$ pressure used here (500 psi cold) evidently did not provide sufficient reduction potential to drive the deoxygenation. Since the reducing potential of the system is defined not merely by the $\mathrm{CO}$ partial pressure, but by the $[\mathrm{CO}] /\left[\mathrm{CO}_{2}\right]$ ratio, the potential may also be increased by chemical or physical removal of $\mathrm{CO}_{2}$. We had hoped that the high solubility of $\mathrm{CO}_{2}$ in the near-critical aqueous pretreatment medium would provide for effective removal of the $\mathrm{CO}_{2}$ from the vicinity of the reaction site. However, it was clearly not enough to bring about the desired reaction. An additional tactic that might be useful would involve generating a fluctuating density within the reaction medium. This fluctuation would produce a sort of "breathing" action that would repeatedly wash $\mathrm{CO}_{2}$ and other reaction products out of the coal pores, and wash in fresh $\mathrm{CO}$. In a static system where the medium in near critical, such density fluctuations could be produced by having a side-arm containing the near-critical fluid, and then imposing a cyclic temperature variation on this side arm (while the main reactor is held at constant temperature). Since the compressibility of liquids becomes very high near the critical point, only small variations in temperature would be necessary for substantial variations in density to result in the main reactor body.

Alternative modifications could involve addition to the pretreatment of some condensedphase reservoir (e.g., a hydroaromatic), or perhaps the use of hydroquinones and other electron transfer agents under nominally non-aqueous (no added water) conditions. Such conditions are, after all, more representative of current liquefaction practice, and would avoid some of the experimental problems known to be associated with excessive water in liquefaction systems. We also believe that it would be helpful to the goal of enhanced oxygen removal during pretreatment (as *** The relative invariability of oxygen loss under various short-term pretreatment conditions observed here is
consistent with the results reported by Loo and Ross. 16 
well as of fundamental interest) to make some actual de-oxygenation rate measurements using some surrogate for the coal phenols (e.g., cresol and/or xylenol mixtures). However, all of these modifications are beyond the scope of this project, and there will be no opportunity to test them before completion of the project.

Lim et al. ${ }^{17}$ have reported results from a similar effort to improve liquefaction yields by means of a $\mathrm{CO} / \mathrm{H}_{2} \mathrm{O}$ pretreatment. They have chosen to operate at slightly lower temperature and higher $\mathrm{CO}$ pressure, apparently projecting that more is to be gained by doubling $\mathrm{CO}$ pressure (e.g., from 400 to $800 \mathrm{psi}$ cold) than is to be lost by decreasing the temperature 20 to $30^{\circ} \mathrm{C}$ and thereby lowering the vapor pressure of water by $\sim 600$ psi. In general terms their results appear to be similar to those described here: modest improvement in subsequent liquefaction yields, but no increase in pretreatment oxygen loss.

At this point, we can summarize our general conclusion for enhanced oxygen removal pretreatment using $\mathrm{CO} / \mathrm{H}_{2} \mathrm{O}$. Without substantial improvement in the pretreatment benefits of added electron-transfer agents, we believe the prognosis for them being a practical pre-additive in an aqueous pretreatment scheme is not good. The improvements resulting from the pretreatment conditions we have tested thus far are significant, amounting to a $9 \mathrm{wt} \%$ (maf) increase in hexanesoluble material (a $20 \%$ improvement on a base-case hexane-soluble yield of $46 \%$ ). However, the $20 \%$ improvement noted above was not with the hydroquinone or TAME, but with promoters already known to be effective under liquefaction conditions (donor solvent) themselves, and already exploited in that context. Furthermore, even if the $\mathrm{CO} / \mathrm{H}_{2} \mathrm{O} /$ electron-transfer-agent had given this $9 \mathrm{wt} \%$ improvement in hexane solubles (and a corresponding) increase in distillate yield, it would remain to be seen whether this could provide any real process advantage, given that the pretreatment conditions are now not greatly lower in temperature/pressure severity than the liquefaction itself. We were well aware at the beginning of this project that the pressure and temperature requirements for straight $\mathrm{CO}$-water systems severely limit their utility as liquefaction approaches per-se, and that significant catalysis would be necessary to overcome these limitations for a $\mathrm{CO}$-water pretreatment. We had obviously hoped to overcome these limitations.

\section{PMRTA Analyses of Pretreated Coals}

Pretreated coals were analyzed by the proton magnetic resonance thermal analysis (PMRTA) by Drs. Leo Lynch and Richard Sakurovs at CSIRO, Australia. For PMRTA, we selected a set of pretreated coals for which the subsequent liquefaction yields varied most widely. The objectives were to (1) determine the temperature-dependent molecular mobility of the pretreated coals to learn how this may correlate with their suscepibility to liquefaction, and (2) obtain information relevant to the question of whether the benefits observed arise because of pre-existing crosslinks that are broken by the pretreatment, or because crosslinking that takes place during liquefaction itself has been inhibited.

We received a the results of PMRTA analysis from CSIRO. Their report is appended. We will discuss these results in light of conversion data in our next Quarterly Report. 


\section{Development of a TGA-Based Simulated Distillation Technique}

In the previous quarterly report we had described the TGA-based simulated distillation apparatus that we had assembled (Figures 1 and 2). We also discussed the rationale behind our design, and also reported that we were encountering several difficulties with the computer interface between the Mettler balance and the temperature controller. We were finally able to solve these difficulties and conduct several experiments to test and calibrate the system.

During an actual run, the thermocouple for measuring the temperature and providing the feedback for the temperature controller will be placed outside the distillation vessel, about $3 \mathrm{~mm}$ away from its outside wall (Figure 2). Although the heated section of the tube is well heatshielded, one expects a significant temperature differential between what is registered by the control thermocouple and that inside the vessel. The size of this temperature differential depends on the size and mass of the distillation vessel, the thermal conductivity of the sweep gas, the heating rate, and the temperature. Thus, the system will need to be calibrated in runs in which a second thermocouple is placed inside the vessel. This placement will necessarily preclude any mass measurements, and so during the calibration runs, we did not record any weight changes.

The location of the control thermocouple is a compromise between easing control by being close to the heat source, and minimizing the temperature differential by being closer to the vaporizing liquid. Use of separate control and measurement thermocouples is a possible future modification that would allow us to effectively eliminate this temperature differential. However, at present we have chosen to impose linear temperature ramps on a single control thermocouple and to determine, in "blank" experiments in which no weight-loss measurements are made, the temperature lag between the control thermocouple and an extra thermocouple inside the distillation vessel (in the liquid layer and touching the inner wall of the vessel). The experiments show, as one would expect, a variable lag, large at first, when heating is begun, and smaller and fairly constant as a temperature of about $150^{\circ} \mathrm{C}$ is passed. This variable temperature lag is then used to adjust the control thermocouple readings during the actual run to reflect the actual temperature within the liquid inside the distillation vessel. Thus the establishment of conditions that suitably mimic the ASTM distillation can be a painstaking procedure, requiring the recording of a "blank" for every temperature program that is tested. However, once a suitable heating regimen is established, all of this adjustment can be automated.

We performed extensive tests on the TGA apparatus in order to define operating parameters that would allow us to satisfactorily mimic an ASTM vacuum distillation of a heavy-oil/resid mixture as a test for providing process relevant distillation data for microautoclave products. We contacted personnel from HRI, CONSOL, CANMET, PETC, and Chevron to solicit advice and obtain appropriate samples for calibration tests. These tests involved varying the heating rate, sweep gas and sweep-gas flow rate, pressure, thermocouple location, pressure sensor location, and reactor- or distillation pot geometry. Our goal was first to be able to reproduce the yield of material that is non-distillable at $1050^{\circ} \mathrm{F} \mathrm{AEBP}$ (as HRI does with its $15-\mathrm{mg}$ scale TGA), and 


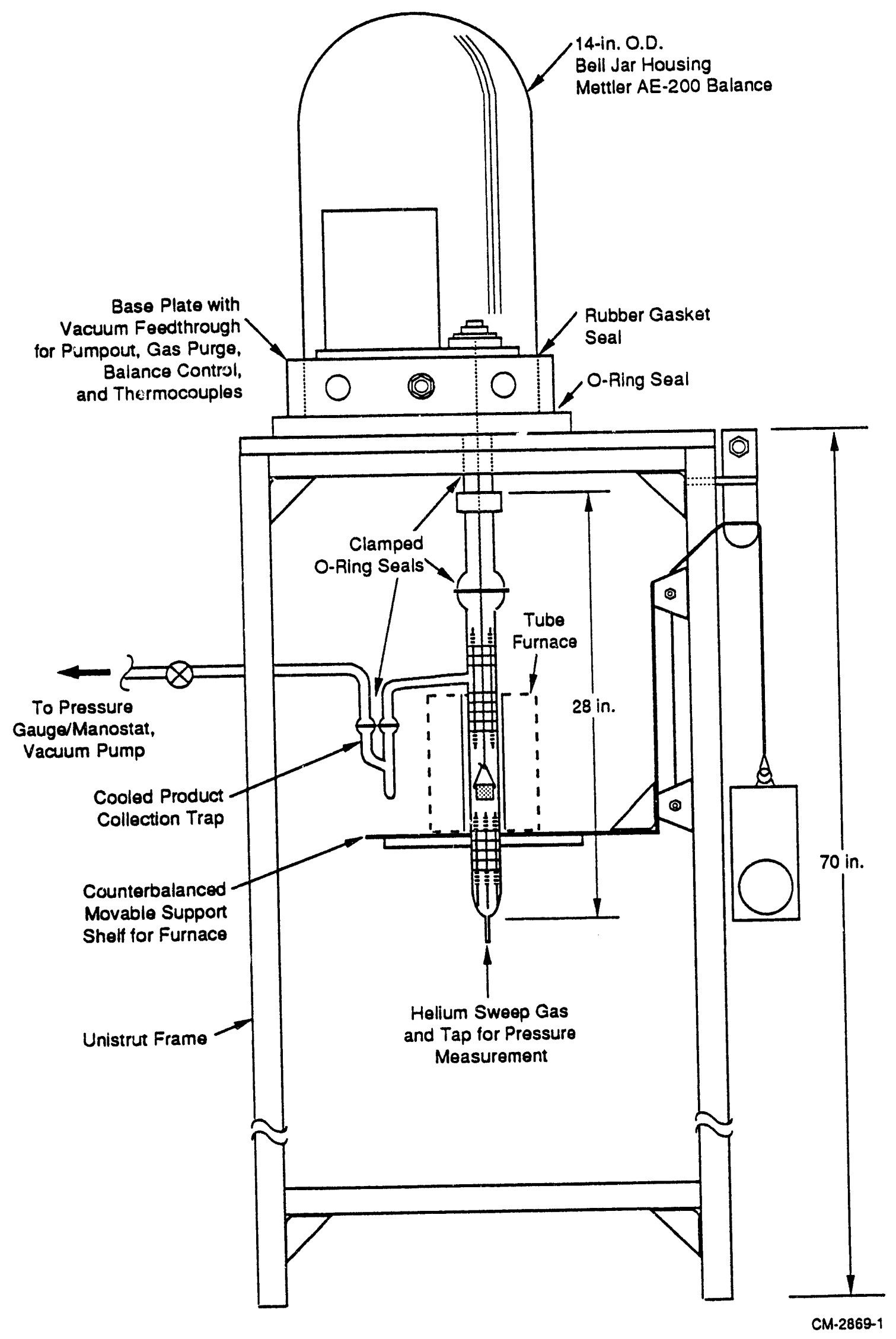

Figure 1. Large capacity vacuum TGA apparatus. 


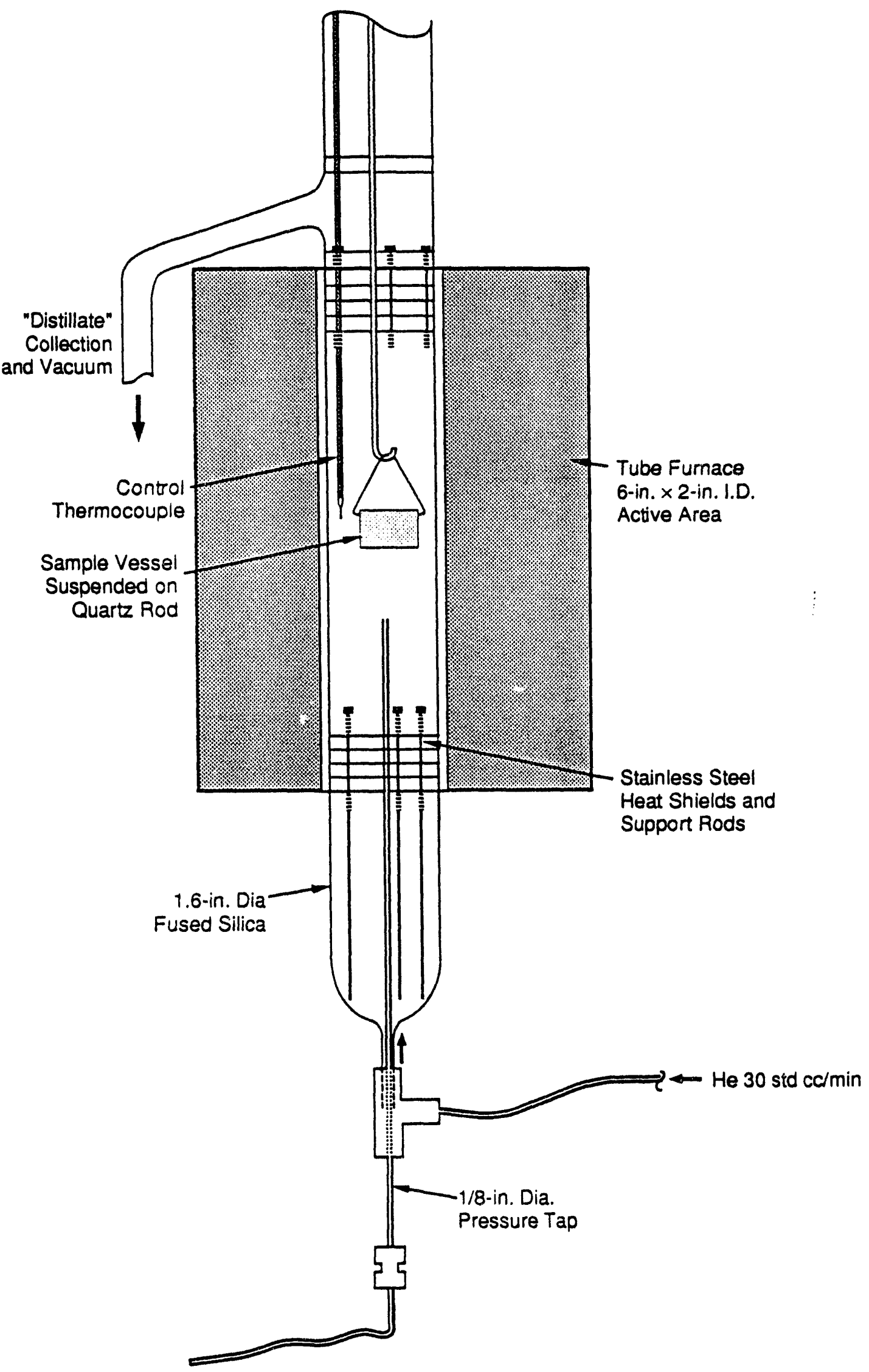

CM-2869-2

Figure 2. Heated portion of vacuum TGA apparatus. 
second, to reproduce as much of the D-1160 distillation curve for the vacuum gas oil fraction as convenient. We feel this latter goal is worthwhile, since it will provide a diagnostic of liquefaction chemistry that has more information than a single-point parameter (i.e., the $1050^{\circ} \mathrm{F}+$ fraction). It is also desirable, in order to meaningfully assess (i.e., discriminate among) materials that are high in materials that are normally considered non-distillables (i.e., $1050^{\circ} \mathrm{F}+$ ), to provide sufficiently good mass transfer through the sample layer and out of the distillation pot that the technique can distill deeply into the "resid" fraction. This will provide maximum additional information about the volatility of material still heavier than a $1050^{\circ} \mathrm{F}$ end point.

Tests to establish a suitable heating regimen have involved the use of a heavy gas oil $\left(635^{\circ} \mathrm{F}\right.$ to $977^{\circ} \mathrm{F}$ ), which we obtained, together with D-1160 data and simulated distillation data, through the courtesy of the CANMET Ottawa laboratory. All of our initial tests showed the fractional weight loss at any adjusted (i.e., "true") temperature to be substantially less than estimated from ASTM correlation. As Ouchi and coworkers have previously dernonstrated, ${ }^{18}$ two readily available parameters that can be used to change the weight loss at a given temperature are the heating rate and the length of the neck of the distillation vessel. Accordingly, we first decreased the heating rate from our initially chosen $10^{\circ} \mathrm{C} / \mathrm{min}$ to $5^{\circ} \mathrm{C} / \mathrm{min}$ (the slowest heating rate we find convenient). When this decrease in heating rate proved insufficient, we changed the sweep gas from argon to helium, in order that the increased diffusivity of helium would increase that mass transport of sample vapors out of the neck of the distillation vessel. When these measures did not easily lead us to a substantially better match of the D-1160 curve, we shortened the distillation vessel from an aspect ratio of about 6.7 to a ratio of 0.7 , using a stainless steel vessel machined to have inside dimensions $1.5-\mathrm{cm}$. height $\times 1.9-\mathrm{cm}$. id.(total volume $3.2 \mathrm{cc}$ ). We had wished to avoid this change in order that we could suspend the entire high pressure reactor [3.7-in. height $x$ 0.75 -in. od $\times 0.125$-in. wall $(9.4 \mathrm{~cm} \times 2.1 \times 0.32 \mathrm{~cm}, \sim 150$ grams, $\sim 12 \mathrm{cc}$ volume $)]$ in the TGA and distill directly from it. However, in the face of having to arrange for a more complicated gas flow path in order to meet the original goal, we have for the present opted to use these low aspect ratio vessels, which are still large enough to accommodate the entire reaction mixture from $0.5 \mathrm{~g}$ of coal and $1 \mathrm{~g}$ solvent. [Note that the increased diameter of these low aspect ratio vessels means that the cross section area is increased 2.25 fold. Thus a given weight of product will have a total depth in the pot that is decreased by a factor of 2.25 (to $\sim 0.5 \mathrm{~cm}$ for a $1.8 \mathrm{-g}$ sample) and a characteristic diffusion time (should vapor transport through the liquid layer be primarily diffusion limited) that is decreased about 5 times.]

An additional difficulty that had to be overcome with a "liquid" layer in the distillation pot that is fairly thick is that of bumping, or splattering. The use of marble boiling chips was, by itself, not sufficient to prevent splattering. We achieved a satisfactory solution to this problem by placing a 16-mesh screen, formed into the shape of a shallow inverted cone, over the top of the pot. This screen prevented any significant splatters from leaving the distillation pot, without substantially inhibiting vapor transport. When all of the above modifications had been made and the TGA parameters adjusted, we obtained the test results described below. 
Figure 3 shows the weight-loss curve for a 2:1 mixture of tetralin and heavy oil $(1.3,0.65$ grams), simulating a whole-product mixture of a liquefaction experiment. At this heating rate and pressure (heat rapidly to $80^{\circ} \mathrm{C}$, hold for 30 min., ramp to $500^{\circ} \mathrm{C}\left(1336^{\circ} \mathrm{F}\right.$ AET at 2.5 torr of $\mathrm{He}$ ) at $10^{\circ} \mathrm{C} / \mathrm{min}$ ), and with the $\mathrm{HGO}$ having an IBP of $635^{\circ} \mathrm{F}$, a distinct plateau separates the tetralin loss from the heavy oil distillation. The lower portion of this curve matches very closely with the CANMET ASTM correlation curve as shown in Figure 4. With the shortened distillation vessel described above, the slower heating rate is not necessary; $10^{\circ} \mathrm{C} / \mathrm{min}$ also provides quite satisfactory results. 


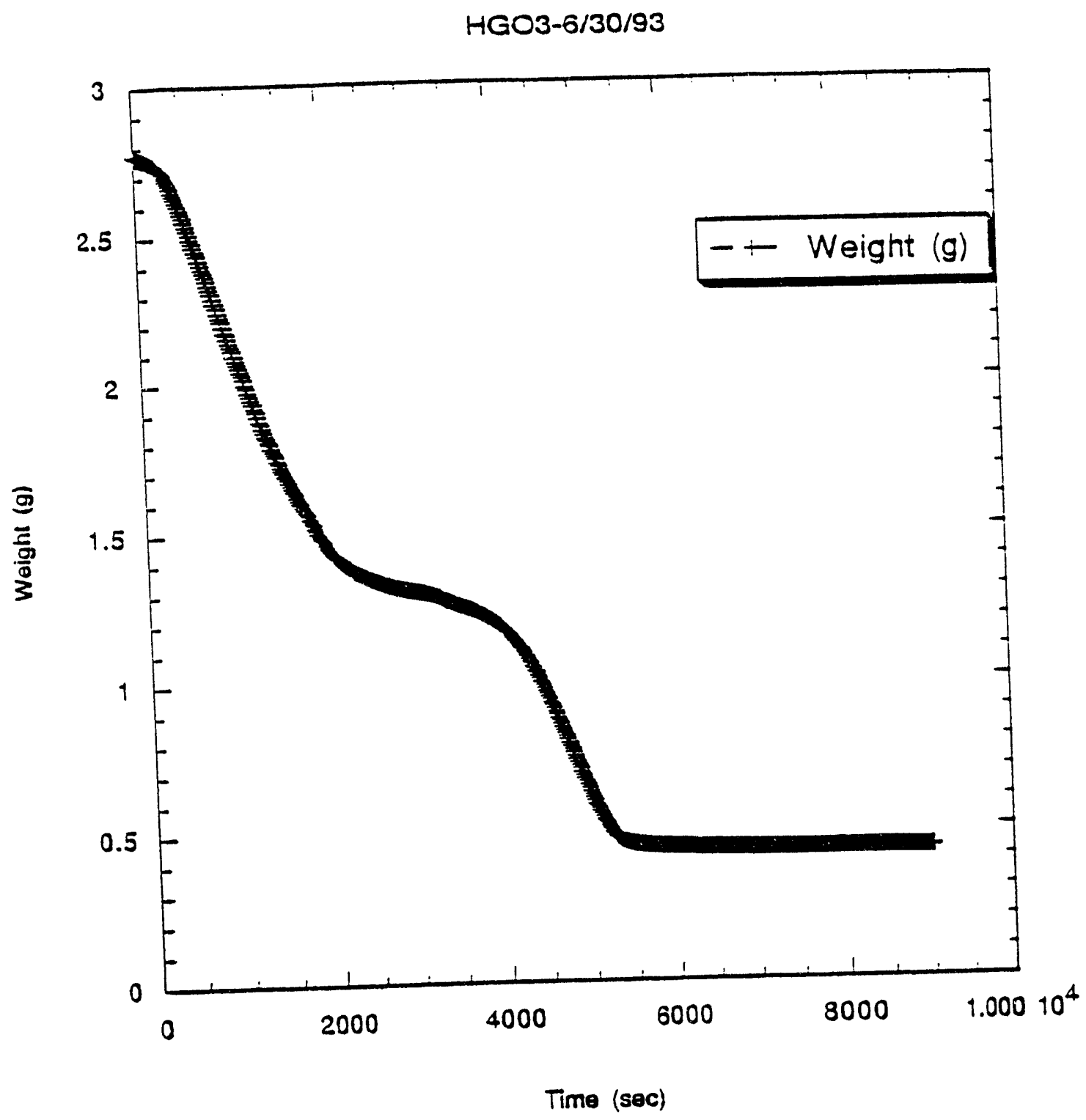

Figure 3. TGA weight-loss curve for a tetralin-heavy gas oil mixture using a short distillation vessel. 


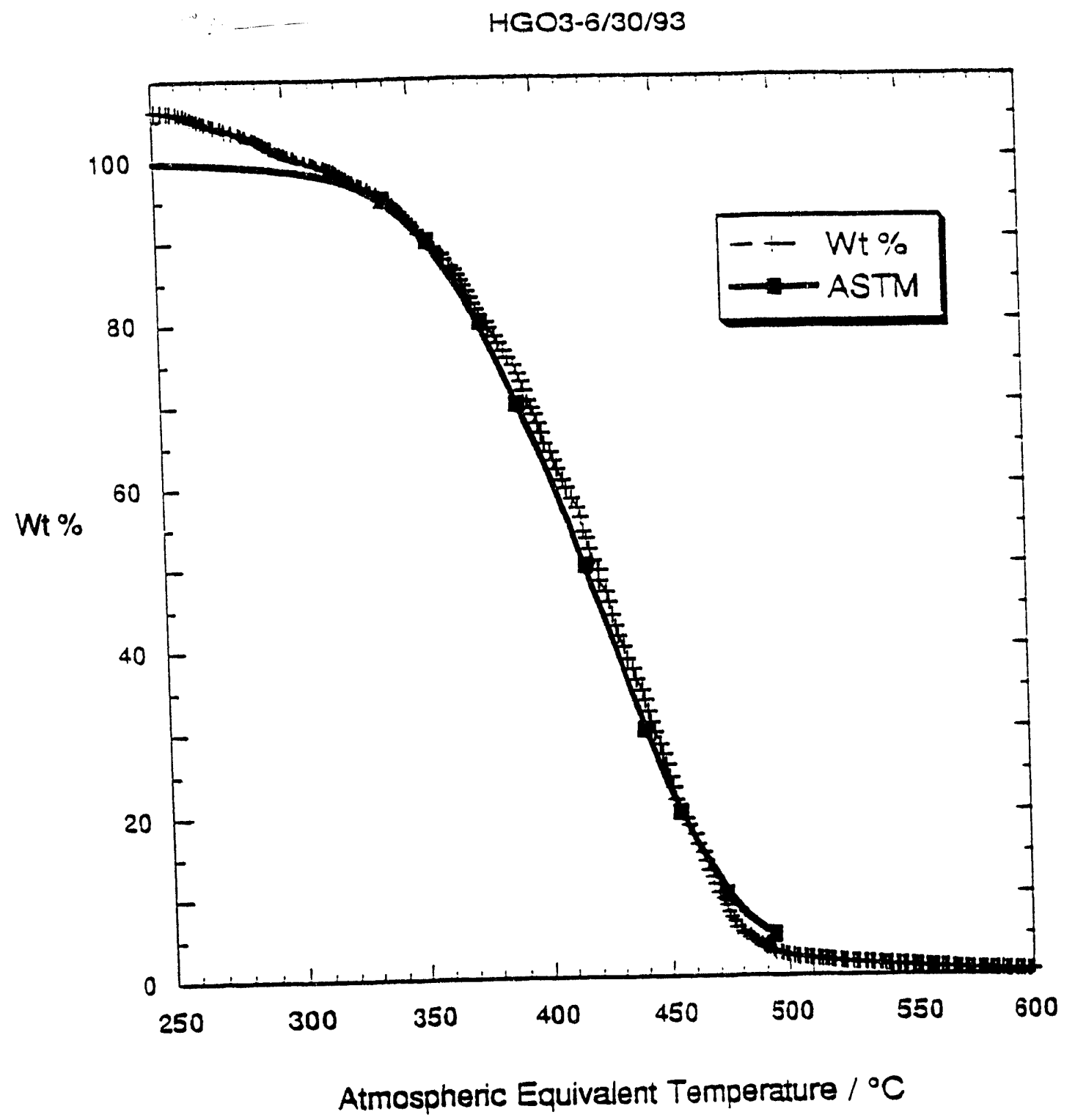

Figure 4. Comparison of the HGO weight-toss portion of Figure 4 with the ASTM HGO distillation. 


\section{REFERENCES}

1. Suuberg, E. M.; Unger, P. E.; Larsen, J. W., Energy \& Fuels 1987, 1, 305.

2. a. Whitehurst, D. D.; Farcasiu, M.; Mitchell, T. O.; Dickert, J. J. Jr., Electrical Power Research Institute Reports AF-252 (1976).

b. Whitehurst, D. D.; Farcasiu, M.; Mitchell, T. O.; Dickert, J. J. Jr., Electrical Power Research Institute Reports AF 480 (1977).

3. McMillen, D. F.; Chang, S. -J.; Fleming, R. H.; Laine, R. M.; Malhotra, R.; Nigenda, E.; Ogier, W., "Effect of of Amine Solvents and Oxygen Functionalities on Coal Liquefaction," EPRI Research Project 2147-5 (1985).

4. Solomon, P. R.; Serio, M. A.; Deshpande, G. V.; Kroo, E., Energy \& Fuels 1990, 4, 42.

5. Moroni, E. C., "Coal Liquefaction and Upgrading Benefit from Heteroatom Removal," 1987 Conference on Coal Science, J. A. Moulijn, K. A. Nater, and H. A. G. Chermin, Eds. (Elsevier, Amsterdam, 1987), p. 351.

6. a. Garg, D., et al., "Effect of Solvent Modification on Coal Liquefaction," DOE Final Report, Contract No. 82PC550003-38 (1985).

b. Sullivan, R.; Frumkin, H., Am. Chem. Soc. Div. Fuel Chem. Preprints 1986, 31(2), 325.

7. Furimsky, E., Catal. Rev.-Sci. Eng. 1983, 25(3), 421.

8. Ross, D. S.; McMillen, D. F., "Exploratory Coprocessing Research," DOE Contract No. DE-AC22-88PC88802, presented at DOE Liquefaction Contractors' Review Meeting, Pittsburgh, PA, October 1989.

9. Appell, H. R.; Miller, R. D.; Illig E. G.; Moroni, E. C.; Steffgen, F. W., DOE Report PETC/TR-79/1 (1979).

10. Sweeny, P. G.; Gutenkunst, V.; Nowok, J.; Stenberg, V. I., Fuel 1991, 70, 74.

11. Fischer, F.; Schrader, H., Brennst.-Chem. 1921, 2, 257.

12. a. Lynch, L. J.; Webster, D. S.; Barton, W. A., "1H NMR Thermal Analysis," Advances in Magnetic Resonance, Vol. 12, (Academic Press, New York, 1988) pp. 385-412.

b. Lynch, L. J.; Sakurovs, R.; Webster, D. S.; Redlich, P. J., Fuel 1988, 67, 1036.

13. Lynch, L. J.; Webster, D. S.; Sakurovs, R; Barton, W.; Maher, T. P., Fuel 1988, 67, 579.

14. Bockrath, B. C., private communication, 1993.

15. a. Plumlee, K. W.; Vernon, L. W., U.S. Patent No. 4,049,536 (1977).

b. Plumlee, K. W.; Vernon, L. W., U.S. Patent No. 4,049,537 (1977).

c. Plumlee, K. W.; Vernon, L. W., U.S. Patent No. 4,051,012 (1977).

16. Loo, B.; Ross, D. S.; "Hydrothermal Pretreatment of Coal," final report, U.S. DOE Contract No. DE-AC22-89-PC89880, April 1991.

17. Lim, S. C.; Rathbone, R. F.; Givens, E. N.; Derbyshire, F. J. Am. Chem. Soc., Div. Fuel Chem. Preprints 1992, 38(2), 618.

18. Mondragon, F.; Ouchi, K. Fuel 1984, 63, 61. 

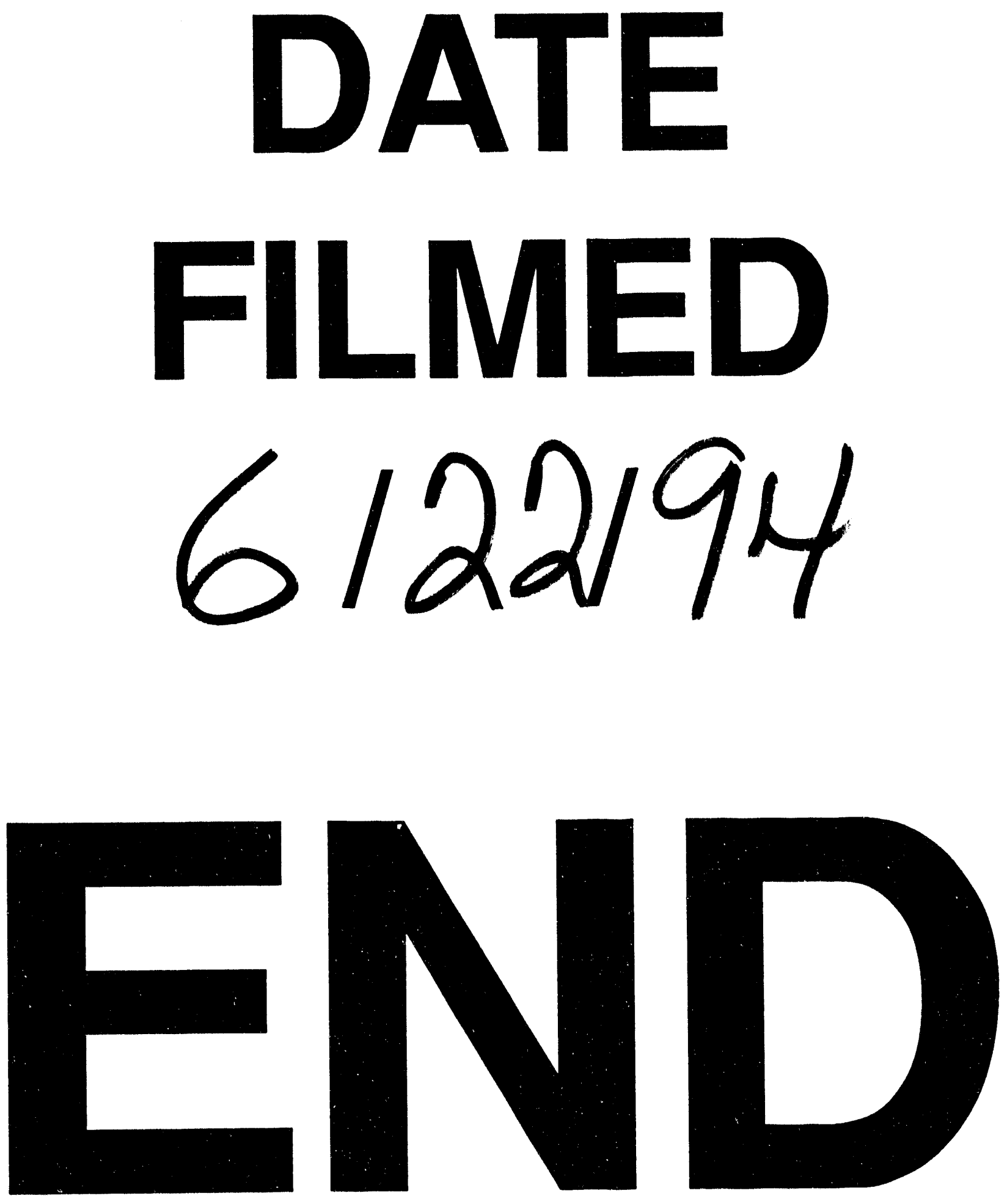
